\title{
The Architectural Complexity of Crown Bud Clusters in Gentian: Anatomy, Ontogeny, and Origin
}

\author{
Uttara C. Samarakoon ${ }^{1,4}$, Keith A. Funnell ${ }^{2}$, and David J. Woolley \\ Institute of Agriculture and Environment, Massey University, Palmerston North, 4474, New Zealand \\ Barbara A. Ambrose ${ }^{3}$ \\ Institute of Molecular BioSciences, Massey University, Palmerston North, 4474, New Zealand
}

Ed R. Morgan

The New Zealand Institute for Plant \& Food Research Limited, Private Bag 11 600, Palmerston North, 4442, New Zealand

\begin{abstract}
Additional INDEX words. adventitious buds, axillary buds, Gentianaceae, hierarchical arrangement of buds, phyllotaxis
ABstract. Shoot productivity and overwintering survival of gentians (Gentiana sp.) are determined by the initiation and subsequent development of crown bud clusters. Understanding of the anatomical features and origins of crown buds and bud clusters, and plant ontogeny, the morphological features of crown buds, and their associated development is required to achieve manipulation of bud initiation, emergence, and development. Anatomical features of the crown bud clusters were examined using both light and confocal microscopy using hybrids of Gentiana triflora $\times$ G. scabra. The initiation of bud clusters presented characteristics typical of adventitious buds in terms of their origin and presence of external vascular connection to the parental tissue. In contrast, crown buds forming subsequently within the cluster developed as axillary buds within that initial bud, collectively forming on a compact stem with minimal internode elongation. Stem elongation within the cluster after application of gibberellic acid enabled identification of a hierarchical arrangement of buds within the cluster with one bud at each node and arranged spirally at $90^{\circ}$. Arrangements of buds within the cluster were different from the opposite decussate phyllotaxis in floral shoots with two axillary buds at each node. Based on the current study, a crown bud cluster originated from a first bud initial, which was adventitious followed by development of subsequent crown buds within the cluster as axillary buds from this first bud initially with a single bud developing at each node.
\end{abstract}

Gentiana (Gentianaceae) comprise 361 species distributed worldwide that are mainly associated with an alpine/mountain habitat (Ho and Liu, 2001; Mabberley, 2008). Most Gentiana species and their hybrids (gentians) are perennial herbs, which use preformed crown buds as part of the perennating structure. For use as an ornamental plant, floral productivity of gentians is associated with the growth and development of these crown buds (Samarakoon et al., 2010, 2012), and the timely initiation of an adequate number of crown buds on plants is perceived as a limiting factor during vegetative propagation in commercial nurseries. However, little is known about the origin and development of these crown buds.

In seedlings of gentians, crown buds arise in the transition zone between shoot and root (Samarakoon et al., 2013) as separate units comprising several associated buds with one such unit comprising two or more buds referred to as a bud cluster

Received for publication 27 Aug. 2013. Accepted for publication 22 Oct. 2013. We thank the New Zealand Foundation for Research, Science and Technology (contract C02X0702), Plant and Food Research CORE funding: 12058-

"Fashionable Plants for the Ornamentals Industry," George Mason Charitable Trust and Massey University Doctoral Scholarship for financial support, and Manawatu Micorscopy and Imaging Centre for technical assistance.

${ }^{1}$ Current address: Department of Horticulture, Clemson University, E-143 Poole Agriculture Center, Clemson, SC 29634.

${ }^{2}$ Current address: The New Zealand Institute for Plant \& Food Research Limited, Private Bag 11 600, Palmerston North, 4442, New Zealand.

${ }^{3}$ Current address: The New York Botanical Garden, 2900 Southern Boulevard, Bronx, NY 10458.

${ }^{4}$ Corresponding author. E-mail: usamara@clemson.edu.
(Samarakoon et al., 2012). Bud clusters are also found in other families such as in Myrtaceae (Burrows et al., 2008) and Cucurbitaceae (Gerrath et al., 2008); however, crown bud clusters in gentians have barely been studied previously. An understanding of morphological features associated with the origins of crown buds and bud clusters, and plant ontogeny, is required to develop techniques for manipulation of bud initiation and shoot emergence for horticulture.

In terms of types of buds, axillary buds are typically of exogenous origin, whereas adventitious buds develop from either endogenous or exogenous tissue (Evert, 2006). Because adventitious shoots are more juvenile compared with axillary shoots (Del Tredici, 2001; Vesk and Westoby, 2004), even if shoots of these two types emerged at the same time, they are likely to develop differently, leading to variation in times at which shoots reach anthesis, a feature of interest in their production for ornamental use. However, in our previous study (Samarakoon et al., 2013), whether the buds within the cluster were axillary or adventitious was not addressed. The presence of a node and a leaf base is regarded as a prerequisite for axillary bud formation (Cutler et al., 2008; Evert, 2006; McConnell and Barton, 1998), whereas adventitious buds are not being related to a leaf axil (Cutler et al., 2008) and can develop from various plant organs (Evert, 2006; Kerstetter and Hake, 1997). In terms of vascular connections and alterations, the presence of an axillary bud at a node created gaps in the vascular cambium of the main shoot (Cutler et al., 2008), whereas adventitious buds could arise endogenously from the 
periphery of the cambium of the vascular cylinder or parenchyma (Bowes, 1996; Evert, 2006) or exogenously from more superficial tissue like the epidermis (Evert, 2006). In the current study, these differences between adventitious and axillary buds, their location of formation, presence of gaps in the vascular ring, vascular connections to the primary stem, and association with scale leaves were identified as strategies to demarcate axillary vs. adventitious buds.

Because individual crown buds colocated within a cluster are the source of floral shoots, their origin is of great importance in controlling the number of shoots, timing of emergence, and duration to flower. In our previous research with gentian, 27\% of crown buds did not emerge within a growth cycle, presumably as a result of paradormancy (Samarakoon et al., 2012). Buds within the cluster could be axillary or adventitious and, if axillary, paradormancy could exist within the buds of the cluster. To identify the growth potential of crown buds within the cluster therefore, a prior understanding of their hierarchical arrangement was required.

We have been using species and hybrids of Gentiana triflora $\times$ G. scabra as a model to understand the morphology and ontogeny of crown buds in gentians (Samarakoon et al., 2013). Like with similar studies with other herbaceous (Chiatante et al., 2008; Myers et al., 1964) and woody perennials (Burrows, 2000; Saravitz et al., 1993; Woo and Wetzstein, 2008), the type of buds that was present was determined by tracing the vascular connection of the buds to the tissue of origin and the morphological identity of this tissue (i.e., shoot/stem, root or transition zone). A similar anatomical approach was applied to gentians to confirm whether bud clusters, and buds within them, are axillary or adventitious in origin; the current study detailed the anatomy and morphology of both bud clusters and the buds within these clusters.

\section{Materials and Methods}

\section{Management of planting material and sampling}

Plant material for Crown bud Clusters: Origin AND ONTOGENy (EXPT. 1). Plants of the gentian cultivar Showtime Diva were propagated by tissue culture at The New Zealand Institute for Plant \& Food Research [Plant \& Food Research (Palmerston North, New Zealand; lat. 40²0' S, long. $175^{\circ} 60^{\prime} \mathrm{E}$ )] using nodal cuttings. Rooted cuttings were deflasked and established in 60-cell trays (45 mL cell volume) containing a bark:pumice media (refer to constituents below) in a greenhouse (heated at $15^{\circ} \mathrm{C}$, ventilated at $20^{\circ} \mathrm{C}$ ) during Mar. 2008. Plants were irrigated using a capillary system, which supplied between 50 and $60 \mathrm{~mL}$ of water per plant per day supplemented with one overhead watering per week. After a root plug was established (May 2008), plants were potted into black polythene bags $(1.7 \mathrm{~L})$ using a growing medium comprising A grade bark $50 \%$, bark fiber $30 \%$, pumice $7 \mathrm{~mm} 20 \%$ with $1 \mathrm{~kg} \cdot \mathrm{m}^{-3}$ serpentine super, $150 \mathrm{~g} \cdot \mathrm{L}^{-1}$ dolomite, $200 \mathrm{~g} \cdot \mathrm{L}^{-1} 16 \mathrm{~N}-3.5 \mathrm{P}-$ 10K controlled-release fertilizer (Osmocote ${ }^{\circledR} 8-9$ month; Everris International, Geldermalsen, The Netherlands), and $100 \mathrm{~g} \cdot \mathrm{L}^{-1}$ $15 \mathrm{~N}-4.8 \mathrm{P}-10.8 \mathrm{~K}$ controlled-release fertilizer (Osmocote ${ }^{\circledR}$ 3-4 month; Everris International). Plants were grown in a heated greenhouse (heated at $15{ }^{\circ} \mathrm{C}$, ventilated at $20{ }^{\circ} \mathrm{C}$ ) under a capillary irrigation system using drippers, which supplied between 50 and $60 \mathrm{~mL}$ of water per plant per day supplemented with one overhead watering per week.

Over a period of three growth cycles, for direct macroscopic observations, plants were sampled at a time interval of 3 months through the end of the third growth cycle. For microscopy, three representative samples of crown tissue and associated bud clusters were taken at 3-month intervals after being deflasked (Fig. 1A) through to when bud clusters were visible on the plant. As described in more detail below, sampling of bud clusters was also determined by the size of the bud clusters.

Plant material: Hierarchical arrangement (Expt. 2). During Expt. 1, the physical compactness of crown bud clusters made it difficult to identify the type of buds within a cluster and their hierarchical arrangement. To resolve these areas of uncertainty, because gibberellins are widely reported to promote cell elongation (Sachs, 1965; Sachs et al., 1959), plants were treated with gibberellic acid $\left(\mathrm{GA}_{3}\right)$, which resulted in elongated crown tissue, to identify the hierarchical arrangement within the cluster.

Plants of genotype 03/04-114 were propagated by tissue culture at Plant \& Food Research, deflasked and grown as described previously, and subsequently grown outside for the first growth cycle. Plants with non-emerged crown buds were subsequently selected and repotted (Oct. 2008) into black polythene bags $(3.4 \mathrm{~L})$ using the growing medium described previously. For their second growth cycle, plants were grown on a drained capillary bench in a heated greenhouse (heated at $15{ }^{\circ} \mathrm{C}$, ventilated at $20^{\circ} \mathrm{C}$ ). During this second growth cycle, when new shoots emerged after removal of the existing shoots (Dec. 2008), either $100 \mathrm{mg} \cdot \mathrm{L}^{-1} \mathrm{GA}_{3}$ (OlChemIm, Olomouc, Czech Republic) or water was applied onto the remaining crown buds, shoots, and exposed crown as a spray to runoff ( $\approx 50 \mathrm{~mL}$ per plant; Jan. 2009). By the end of this second growth cycle (July 2009), plants treated with $\mathrm{GA}_{3}$ developed elongated stems within the clusters, resulting in a physical separation of individual buds.

There were eight replicate plants per treatment, each producing between one and five bud clusters per plant. Five individual replicate samples each of the elongated stem with crown buds from $\mathrm{GA}_{3}$-treated plants, or non-elongated stem with bud clusters from control-treated plants, were taken for dissection and confocal microscopy in Oct. 2009. Samples of floral shoots and storage root were also collected.

\section{Light microscopy}

For plants grown for both Expts. 1 and 2, samples of fresh tissue were fixed and embedded in 100\% Paraplast X-tra (McCormick Scientific, Richmond, IL) as described previously (Samarakoon et al., 2013). Depending on the type of tissue, both transverse and longitudinal sections were cut at 8 to $12 \mu \mathrm{m}$ thickness using a rotary microtome (RM 2145; Leica Microsystems, Wetzlar, Germany) and mounted onto polysine-coated slides after staining with $0.05 \%$ toluidine blue. To identify the vascular connections and buds within the crown tissue, and the arrangement of buds within the clusters, transverse and longitudinal sections were taken progressively along the length of crown tissue or buds. The bud clusters initiated at the lowest node (Fig. 1C) were the most reliable source for anatomical tracking of the progressive development of vascular connections of the crown bud cluster, like at the junction of the storage root and shoot where crown buds also arose; the cellular tissue was not well organized.

Morphological features of crown buds and crown tissue were recorded by observing mounted sections using either a compound light microscope (Zeiss, Oberkochen, Germany) or stereo microscope (Leica Microsystems) with a digital camera 

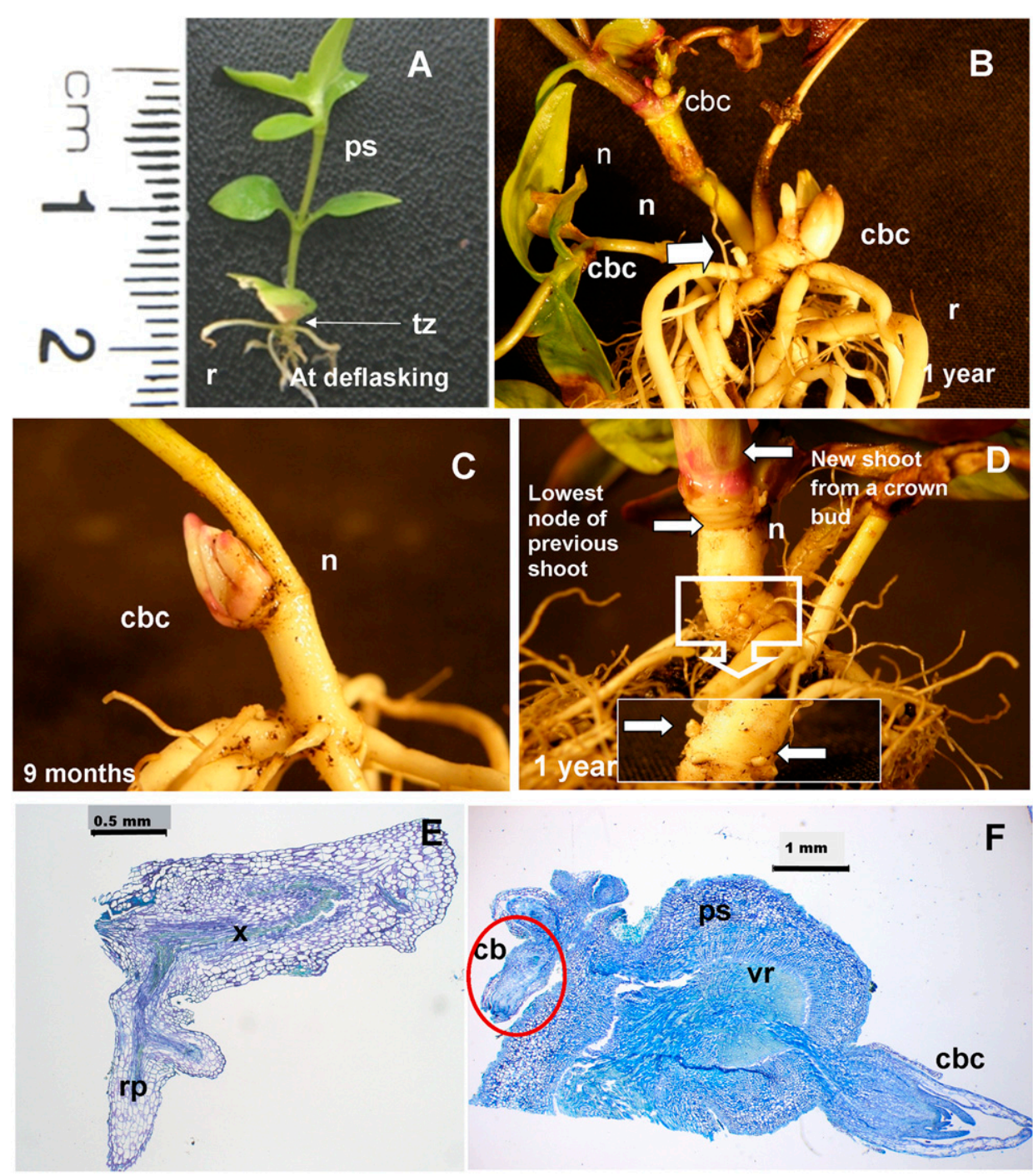

Fig. 1. Development of the transition zone and bud clusters from different positions on plants of gentian cultivar Showtime Diva produced from tissue culture at different periods after being deflasked; (A) intact plant when deflasked indicating transition zone; (B) bud development at different positions on a single plant after 1 year (June 2009; white arrow indicates a cluster arising from proximal end of storage roots); (C) bud cluster developed at a node after 9 months; (D) thickening of the region below the lowest node after 1 year; magnified view within white-colored square illustrating crown buds (white arrows). (E) Transverse section of an eventual transition zone of a plant of 'Showtime Diva' derived from tissue culture after being deflasked. (F) Section through crown bud clusters initiated at different positions at the root end of eventual transition zone from two positions, one at a distance from the main shoot (red circle) and other with connection to the primary shoot. As indicated by staining with Toluidine blue, tissue stained light blue are xylem vessels. $\mathrm{cb}=\mathrm{crown}$ bud; $\mathrm{cbc}=$ crown bud cluster; $\mathrm{cs}=$ crown shoot; $\mathrm{n}=$ node; $\mathrm{r}=$ roots; $\mathrm{ps}=$ primary shoot; $\mathrm{rp}=$ root primordia; $\mathrm{tz}=$ transition zone; $\mathrm{x}=$ xylem strands; $\mathrm{vr}=$ vascular ring.

attached (DFC 320; Leica Microsystems). Based on observations made of the sections, the developmental sequence of crown tissue and bud clusters was identified. The number of individual buds present, within a single crown bud cluster, was used to identify the progressive stages of the development of buds within the cluster (i.e., Stages 1 to 3; refer to "Results and Discussion").

\section{Confocal microscopy}

Fresh samples were either sectioned by hand or using a cryotome (Jung CM 1800; Leica Microsystems) to 20 to $30 \mu \mathrm{m}$ thickness. In Expt. 2, for plants treated with $\mathrm{GA}_{3}$, sectioning was performed at different positions along the elongated stem.
In control treatments, sections were taken at the proximal end of the cluster stem and also from the proximal end of floral shoots. Fresh tissue sections were washed with phosphate-buffered saline (PBS) and 2\% Tween 20 (Sigma-Aldrich, St. Louis, MO) for $10 \mathrm{~min}$, stained with $0.01 \%$ Acridine orange $(\mathrm{AO})$ for $1 \mathrm{~h}$ at room temperature, and washed with PBS (Yang et al., 2007). Slides were observed under a confocal microscope (Leica Microsystems) with lignified cell walls giving autofluorescence and non-lignified walls giving fluorescence stained with AO.

\section{Macroscopic observations}

In Expt. 2, the presence of buds, shoots, and bud clusters was observed relative to their location of development within the cluster. Bud clusters were dissected and, based on the location of crown buds and scale leaves on the cluster stem, the order of arrangement/formation of buds within the clusters was determined.

\section{Results and Discussion}

\section{Crown bud clusters: Origin and ontogeny}

Macroscopic features of INITIATION OF BUD CLUSTERS. We found that crown bud clusters developed from multiple positions (Figs. 1B-D and 1F). During the first growth cycle after being deflasked, bud clusters were most commonly initiated at the base of the primary shoot, where the shoot and storage roots joined (Fig. 1B). Bud clusters were also evident at the lower nodes on the primary shoot (Fig. 1B-C) and from the proximal end of the storage roots (Fig. 1B). In plants with bud clusters at the lowest node, swelling of the shoot, in the area below the lowest node, was clearly visible as the growth cycle progressed (Fig. 1C-D). Irrespective of where the crown bud clusters formed, in line with the natural seasonal growth cycle, the primary shoot above the crown bud cluster senesced during subsequent months, and the region of shoot below the bud cluster thickened (Fig. 1D). On the thickened primary shoot below the cluster, small buds formed on the surface (magnified insert Fig. 1D), some of which also developed into crown bud clusters. Hence, as was apparent in more mature clonally propagated plants, the area below the lowest node on the shoot progressed to become the rhizome of the crown (Fig. 1B); i.e., like in the transition zone of seedlings (Samarakoon et al., 2013). Crown buds were typically 
colocated as a cluster on the transition zone; i.e., a crown bud cluster (Fig. 1B-C).

ANATOMICAL FEATURES OF THE INITIATION OF BUD CLUSTERS. Soon after being deflasked, the sections of the shoot where the transition zone would subsequently form comprised tissues that were not organized [i.e., no organized vascular arrangement (Fig. 1E)] typical of shoot, root, or transition zone (Samarakoon et al., 2013), and were, therefore, termed the pre-transition zone. Compared with the transition zone in "true" seedlings (Samarakoon et al., 2013), clonally propagated plants appeared rather disorganized at the proximal end of the transition zone even when well established [i.e., 6 months after deflasking (Fig. $1 \mathrm{~F})$ ]. Although not visible macroscopically, it was possible to identify different positions of initiation of crown bud clusters within both longitudinal and transverse sections of the eventual transition zone. Most plants had crown bud clusters with primordia originating from the base of the primary shoot (Fig. 1F) but with vascular connections to the cells located external to the vascular ring (i.e., no gaps were formed in the vascular ring). Although attached externally to the base of the primary shoot, xylem strands were visible within the vascular connection (Fig. 1F). However, in contrast, some of the plants had buds developing on the root end of the transition zone, which was in close association to the proximal end of storage roots (Fig. 1F). In addition to these examples, there were crown bud clusters attached at the lowest node (Figs. 2A-G and 3A-D). Hence, bud clusters were able to form at multiple positions, even on a single plant, and presented different degrees of development in their vascular connections. Although the typical anatomical characteristics of the transition zone in a seedling such as vascular organization (Samarakoon et al., 2013) were not evident within these clonally propagated plants (Figs. 1 to 3 ), the swelling of the shoot below the lower nodes and the base of the shoot was the site for formation of crown buds and was similar in function to the transition zone in a seedling.

\section{Origin and ontogeny of development of bud primordia and buds within the cluster}

Different levels of development within the cluster (i.e., from the presence of two buds through to many buds) were used to delineate progressive stages of development of the cluster and defined as Stages 1 to 4 (Figs. 2 and 3). Additionally, the ontogeny of development of the first bud primordium for the cluster, and the crown bud cluster within these stages, enabled identification of axillary and adventitious origin of the buds as discussed later.

Stage 1-Two to three buds in The Cluster. At Stage 1, the crown bud cluster was not yet macroscopically visible but comprised two to three buds (Figs. 2D and 2H). When a bud formed on the shoot, which would eventually form a cluster (Fig. 2D), sectioned acropetally at this stage, the presence of this bud did not cause major changes to the vascular ring of the shoot (Fig. 2A) in contrast to what occurs with axillary buds on the floral shoot (Samarakoon et al., 2013). This developing bud cluster developed external to the vascular ring on one side of the primary shoot; i.e., eventual transition zone (Fig. 2B-C). The base of this bud cluster was visible as a single mass of cells (Fig. 2C), which appeared rather disorganized compared with that evident in a typical flowering shoot, root, or fully developed transition zone evident in seedlings (Samarakoon et al., 2013). Progressing acropetally from this position, the primordia of the two buds were evident (Fig. 2D). Based on position, the smaller bud appeared to be axillary, but a vascular connection between the two buds was not evident (Fig. 2C-D). Even in longitudinal sections, organized vascular connections were not visible between buds within a cluster at this stage (Fig. $2 \mathrm{H}$ ), as evident within Stage 3, as a result of the buds not being arranged on a single plane of axis within the sections.

Stage 2-FOUR to Five BUdS IN THE CLUSTER. The crown bud cluster was macroscopically visible as a small, single structure, at Stage 2, and contained between four and five crown buds (Fig. 2F-G). In contrast to what occurs with axillary buds on the floral shoot (Samarakoon et al., 2013), the base of the bud cluster formed externally on the shoot (Fig. 2E). Based on the identification of a vascular ring at the base of the bud cluster cells, the cluster could be identified as having a stem axis of its own (Fig. 2E). With sections progressing acropetally from the base of the cluster, the presence of five buds of varying sizes was revealed (Fig. 2F-G). The bud in the middle, presumably the apical bud (Fig. 2G), had visible vascular differentiation below it, connecting to the two buds at either side (Fig. 2F). Not all buds were visible in a single longitudinal section of a crown bud cluster at Stage 2, because buds were located on different planes of axis and the vascular connections between the individual buds were not visible (Fig. 2I).

STAGE 3-SiX OR MORE BUDS WITHIN THE CLUSTER. When bud clusters were clearly visible macroscopically (Fig. 3A), on the side of the eventual transition zone where the bud cluster developed, a major change was visible on the primary shoot (eventual transition zone) as an outgrowth of the cortex (Fig. 3B-D). Within this, the crown bud cluster developed a vascular strand connecting the bud directly to the stele without formation of a gap in the vascular ring. The gap in the vascular ring apparent on the opposite side of the cluster at the same node on the primary shoot was possibly the position of the original axillary bud that had senesced (Figs. 3A, 3C, and 3D).

Although there were two axillary buds present at a node of a floral shoot, when bud clusters were initiated at the lowest node, only one bud cluster developed (Figs. 2 and 3). Although six or more buds were present within the cluster at Stage 4 (Fig. $3 \mathrm{E}-\mathrm{G})$, the entire cluster was enveloped by a scale leaf (Fig. 3E) and macroscopically it was visible as a single, enlarged bud structure (Fig. 3A).

Based on the presence of the vascular ring at the distal end of the cluster, the base of the cluster could be identified as a stem (i.e., cluster stem) (Fig. 3F). The axis of the cluster was positioned at the side in this cluster rather than at its center (Fig. 3E-F). Two buds were visible at the proximal end of the cluster stem and, as revealed with progressive acropetal sections, the presence of several more buds became evident (Fig. 3E-G). It was concluded therefore that the buds produced initially in the cluster diverged from the apex of the cluster's axis (Fig. 3G). The earliest formed crown buds had well-developed primordia (Fig. $3 \mathrm{H}$ ) and contained more buds arising from the axillaries (Fig. 3E-F). Vascular connections to the main axis from the buds were not visible at the proximal end but were visible at the distal end of the cluster's axis (Fig. 3I).

\section{Origin for bud clusters; adventitious or axillary?}

Based on the macroscopic and microscopic features of clonally propagated plants, crown bud clusters developed on the transition zone, which could include axils of lower nodes (Figs. 1, 2, and 3), thickened shoot tissue below the first node (Fig. 1D), the base of the shoot (Figs. 1B and $1 \mathrm{~F}$ ) and the proximal end of storage roots 

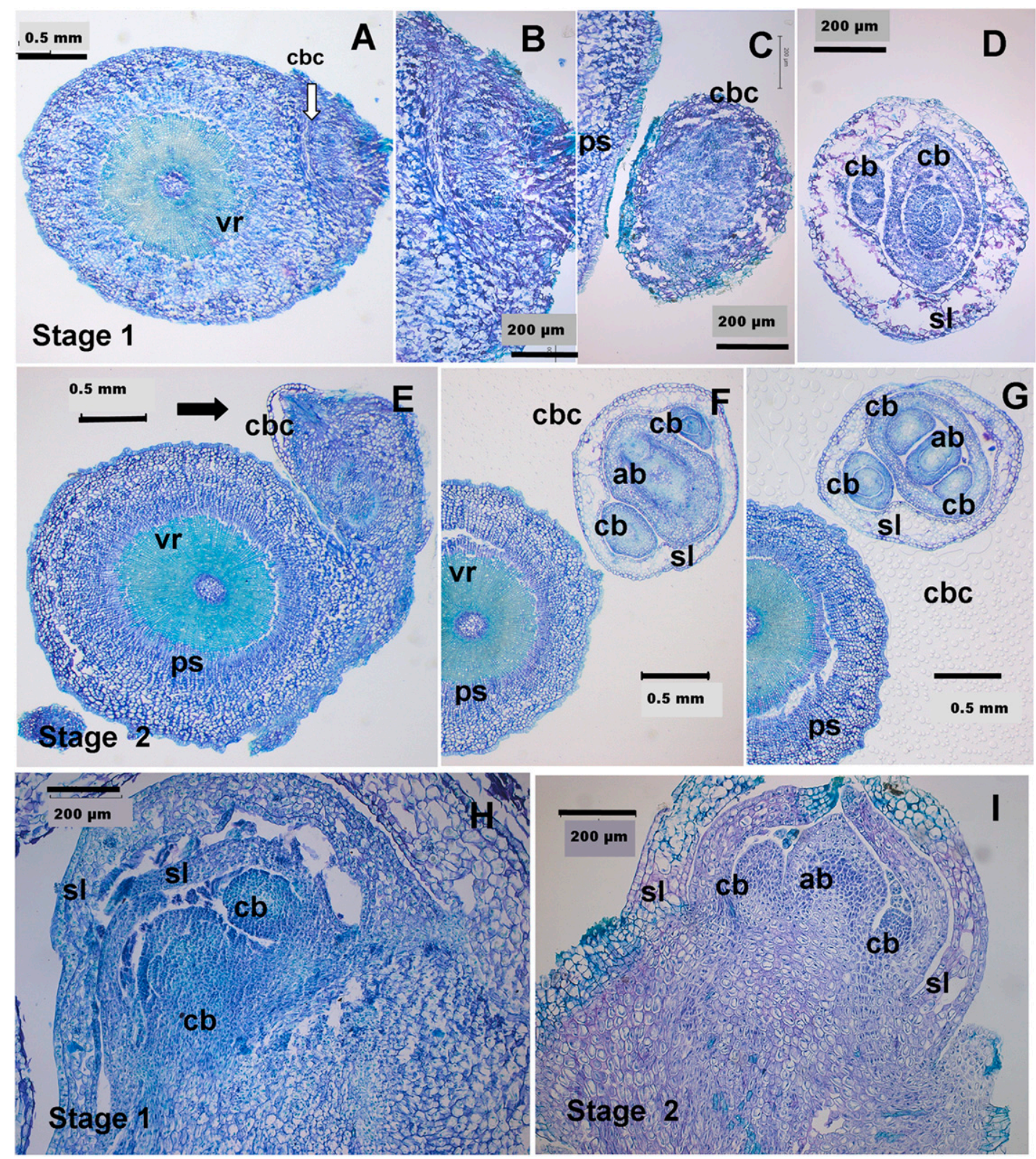

Fig. 2. Sections through bud clusters on eventual transition zone of plants of gentian cultivar Showtime Diva derived from tissue culture at 6 months from being deflasked; (A-D) acropetal sequence of transverse sections below, and through, the bud cluster at Stage 1 (white arrow), indicating magnified images of (B-C) non-differentiated tissue at attachment to main shoot and (D) association between buds within the cluster. (E-G) Acropetal sequence of sections through the bud cluster indicating changes along the bud cluster at Stage 2 (black arrow), (E) at the base of the cluster indicating changes in the vascular ring and the initiation of a crown bud cluster (white arrow) at the node; and (F-G) arrangement of buds within the cluster. (H-I) Longitudinal sections through crown bud clusters to show the association between buds and scale leaves, from plants with crown bud clusters at (H) Stage 1, i.e., two crown buds in the cluster, (I) at Stage 2, three to four

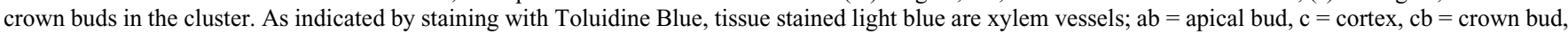
$\mathrm{cbc}=$ crown bud cluster. $\mathrm{ps}=$ primary shoot; $\mathrm{sl}=$ scale leaves; $\mathrm{vr}=$ vascular ring.

(Figs. 1B and 1F). In contrast, on floral shoots, axillary buds were developed from, and associated with, a node within the axils of a leaf base (Samarakoon et al., 2013). In the cultivar Showtime Spotlight, formation of crown buds was also observed at the distal end of storage roots (Samarakoon et al., 2010, 2012) but at a low frequency. The first bud initial of the crown bud cluster was, therefore, initiated without the presence of a node and a leaf base, which is regarded as a prerequisite for axillary bud formation (Cutler et al., 2008; Evert, 2006; McConnell and Barton, 1998) and, therefore, supports the conclusion that the origin of a crown bud cluster is not through an axillary bud. As noted in other plant species, axillary buds differ from adventitious buds by adventitious buds not being related to a leaf axil (Cutler et al., 2008) and can develop from root, hypocotyls, leaf, or the shoot (Evert, 2006). Hence, based on the location of their development, and their ability to develop without a leaf axil, the first bud initials from which crown bud clusters develop must be considered to be adventitious. Bud formation from multiple organs of the plant was similarly observed in Euphorbia esula (Myers et al., 1964), in which adventitious buds formed exogenously or endogenously (Raju, 1975) and hence may be a common occurrence in some herbaceous perennials. 

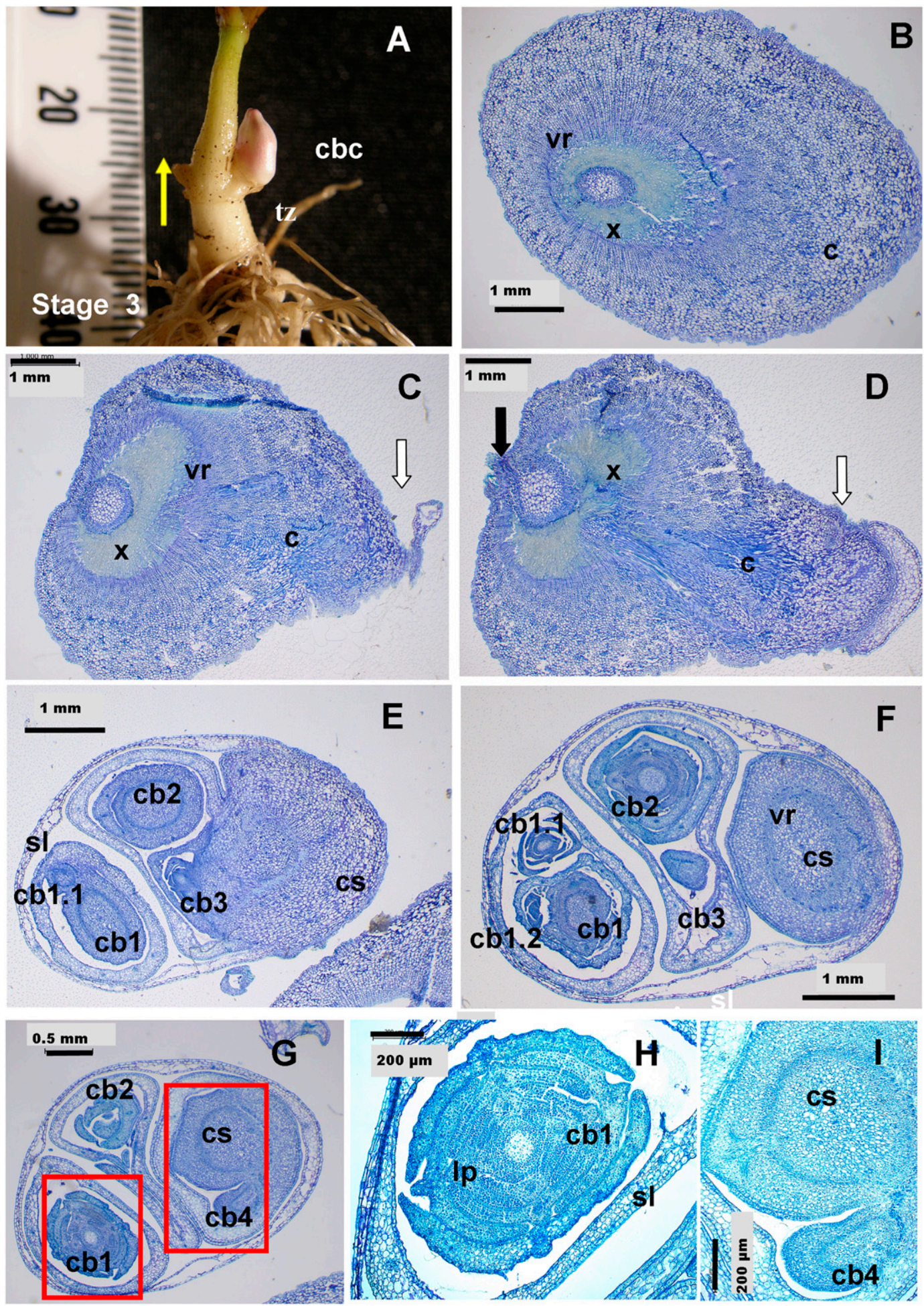

Fig. 3. Acropetal sequence of transverse sections through the eventual transition zone (i.e., shoot/yellow arrow) and a bud cluster at Stage 3 of cluster development of a plant of gentian cultivar Showtime Diva derived from tissue culture at 8 months from being deflasked; (A) intact plant indicating transition zone and crown bud cluster; (B) section at the base of shoot illustrating enlarged cortex and, (C-D) development of the bud cluster on the shoot (white arrow), and the gap in the vascular ring on the other side (black arrow). (E-G) The crown bud cluster, illustrating the arrangement of buds within a cluster at Stage 3 with early initiated crown buds numbered as cb1 (oldest), cb2, cb3, and axillary buds of these buds as cb1.1 and cb1.2. Positions indicated in $(\mathbf{G})$ are magnified in (H) to indicate the greater number of primordia within the earliest initiated bud (cb1) of the cluster axillary buds and (I) to indicate latest bud initiated from the cluster stem. As indicated by staining with Toluidine blue, tissue stained light blue are xylem vessels. $\mathrm{c}=\mathrm{cortex} ; \mathrm{cb}=$ crown bud; $\mathrm{cbc}=\mathrm{crown}$ bud cluster; $\mathrm{cs}=\mathrm{cluster}$ stem; $1 \mathrm{p}=$ leaf primordium; $\mathrm{s}=$ scale leaf; $\mathrm{t} z=$ transition zone; $\mathrm{vr}=$ vascular ring; $\mathrm{x}=$ xylem vessels 
Although the formation of crown buds was more prominent at the base of the shoot, during the first growth cycle in these clonally propagated plants, some crown bud clusters developed around the lower node and were externally apparent as axillary buds (Figs. 1C, 2, and 3) and, therefore, raises the question whether adventitious buds (i.e., the initial bud of a cluster) could be formed within axils of a shoot. Because adventitious buds can originate from parenchyma or cambial cells on any plant organ (Evert, 2006; Kerstetter and Hake, 1997), it was hypothesized that nodes could also be a site for adventitious bud formation before becoming part of the transition zone.

The presence of an axillary bud at a node created gaps in the vascular cambium of the main shoot (Cutler et al., 2008; Samarakoon et al., 2013), whereas adventitious buds could arise endogenously from the periphery of the cambium of the vascular cylinder or parenchyma (Bowes, 1996; Evert, 2006) or exogenously from more superficial tissue like the epidermis (Evert, 2006) of any plant organ (Kerstetter and Hake, 1997). As evident by microscopic examination of crown bud clusters at the proximal end of the shoot (i.e., no visible node present), there were no gaps in the vascular ring, but rather buds initiated externally outside the central vascular cylinder (Fig. 1F). Even when bud clusters developed on one side of the node on a shoot, the bud clusters were attached to the vascular cambium externally, and no disruption to the central vascular cylinder was observed (Figs. 2A, 2E, and 3C-D) as compared with a true axillary bud on the node (Fig. 3C-D). This evidence, therefore, also supports the notion that crown bud clusters originate adventitiously in these clonally propagated plants and is in contrast to seedlings, wherein crown buds formed from the vascular strands arising from the vascular groupings within the transition zone (Samarakoon et al., 2013).

Based on the preceding evidence therefore, the vascular connection of the bud initial for the crown bud cluster was different from that seen with typical axillary buds and could be considered adventitious in origin. Thus, the initiation of a crown bud cluster in these gentian hybrids presents characteristics typical of an adventitious bud in terms of their origin and vascular connection to the parental tissue.

It is interesting to note that the location of formation of adventitious buds could be associated with internal locations of vascular strands; i.e., distance to the periderm at the transition zone of a seedling (Samarakoon et al., 2013), a gap in the vascular ring created by an existing axillary bud (Figs. 2 and 3 ). Understanding how this is determined within the plant will enable manipulation of adventitious bud formation.
Macroscopic and microscopic features of the crown bud cluster

After 7 months of growth, plants developed bud clusters, which were compact, being tightly enveloped with scale leaves. In contrast, plants treated with $\mathrm{GA}_{3}$ developed clusters with individual buds within the cluster physically separated along an elongated cluster stem. On these elongated cluster stems, the scale leaves were elongated and loosely arranged along its length and covered the crown buds at the distal end (Fig. 4A). The elongated cluster stem made it visually easier to identify the relationship between buds in the cluster when treated with

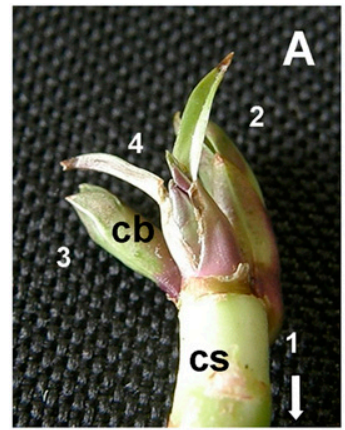

3
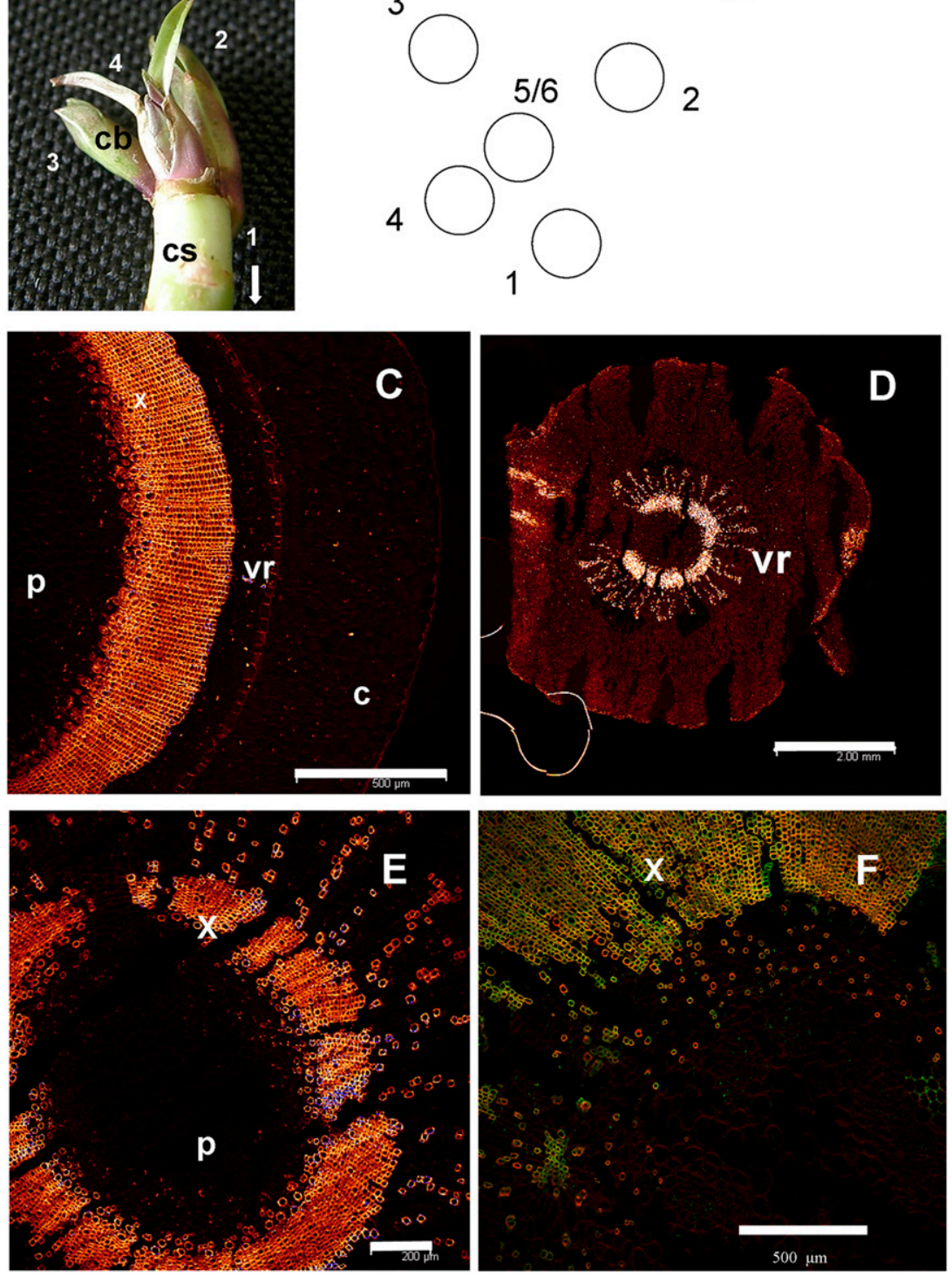

Fig. 4. Plant of gentian genotype 03/04-114 10 months after treatment application with either gibberellic acid $\left(\mathrm{GA}_{3}\right)$ or control. (A) Elongated stem of the cluster with separated buds at the distal end after treatment application of $\mathrm{GA}_{3}$. (B) Diagrammatic illustration of arrangement of buds within the cluster after progressive dissection of a bud cluster on an elongated stem after foliar application of $\mathrm{GA}_{3}$ : earliest formed axillary bud (1) to the last (5). More buds, including the apical bud of the stem cluster, were present within crown bud 5, i.e., 5/6. (C-F) Transverse sections viewed using confocal microscopy $(\mathbf{C})$ at the base of the floral shoot illustrating the vascular ring. (D) The elongated cluster stem after treatment with $\mathrm{GA}_{3}$ with the center magnified in $(\mathbf{E})$ to illustrate the vascular ring similar to stem. (F) Arrangement of xylem vessels at base of the cluster in control treatment. As indicated by autofluorescence and staining with acridine orange, tissues with orange and red fluorescence are the xylem vessels. $\mathrm{c}=$ cortex; $\mathrm{cb}=$ crown bud; $\mathrm{cs}=$ cluster stem; $\mathrm{p}=$ pith; $\mathrm{vr}=$ vascular ring; $\mathrm{x}=\mathrm{xylem}$. 
$\mathrm{GA}_{3}$. The comparative maturity and order of arrangement of crown buds within a cluster was determined by the location of scale leaves and buds on the elongated stem; i.e., the buds at the proximal end were considered most mature. Acropetal dissection of bud clusters on the elongated cluster stem revealed a hierarchical arrangement with one bud at each node at an $\approx 90^{\circ}$ angle between buds (Fig. 4B). Whereas the earliest initiated buds were present individually on the cluster stem, smaller crown buds were present toward the apex as a single unit covered in scales (Fig. 4A-B). As each bud scale was removed on this unit, two buds were visible. One was a separate and well-developed crown bud, and the second comprised a bud containing more buds and scale leaves. It was concluded therefore that the apical meristem of the cluster was located within the latter complex.

Within the control treatment, transverse sections from the proximal end of the floral shoot showed secondary thickening with xylem vessels arranged as a ring (Fig. 4C) as typical of that seen in floral shoots in other species (Bowes, 1996; Chaffey et al., 2002; Evert, 2006), confirming observations made with light microscopy (Samarakoon et al., 2013). By contrast in the regions of the stem with bud clusters, the xylem ring had rays of xylem vessels radiating out of the ring (Fig. 4D-E). At the proximal end of the elongated stem, lignified tissues were arranged as a circle with a larger cortex. Compared with that evident in elongated stems, the base of the crown bud cluster in plants from the control treatment was more disorganized. This comparative disorganization resulted from several buds developing from the same apparent plane of axis, leading to distortion of the tissues within the stem. However, in contrast, the arrangement of lignified cells was the same in both control and $\mathrm{GA}_{3}$-treated plants (Fig. 4E-F). Thus, it could be hypothesized that gibberellin would have activated the sub-apical meristem (Sachs, 1965; Sachs et al., 1959) to produce an elongated stem, whereas under natural conditions, the sub-apical meristem would be compressed in the cluster stem.

\section{Buds within the cluster: axillary or adventitious?}

Whereas the connection between the base of the crown bud cluster and the transition zone was addressed previously, the vascular connections and progressive development of buds within the cluster itself are discussed in the current section. Although the first bud in the cluster initiated adventitiously, buds within the cluster had several buds enclosed within a single scale leaf, being typical therefore of axillary buds. Whereas a clear vascular connection to a main axis was not evident during early ontogeny of a cluster (Stages 1 to 2), they were evident later [Stage 3 (Fig. 3)] and, together with developed scale leaves and vascular gaps in the main axis (Cutler et al., 2008), this observation confirmed the origins of these subsequent crown buds as axillary. However, similar-sized buds were apparent from the same mass of meristematic tissue in the earliest formed buds in these crown buds. the cluster (Figs. 2 and 3), and it appears that these earliest formed buds were not connected to the apical bud through vascular connections, as found with typical axillary buds on a floral shoot (Samarakoon et al., 2013). As clarified within Expt. 2, the absence of visible vascular connections was a result of compactness of the cluster stem, as discussed subsequently.

When elongated after application of $\mathrm{GA}_{3}$, macroscopically the tissue to which crown buds were attached, i.e., the cluster stem, presented characteristics typical of a shoot/stem (Fig. 4), scale leaves were present along the cluster stem, and individual crown buds were associated with scale leaves with only one bud at each node (Fig. 4). Additionally, transverse sections of the elongated cluster stem presented a vascular arrangement as a ring, as observed previously on floral shoots (Fig. 4). In contrast, stems were typically compressed at the base of the cluster, so a vascular ring was not clearly visible under natural conditions. It is hypothesized that several buds develop in close proximity to each other causing distortion to the cluster stem when compact. Other than the apical bud, all crown buds within the cluster were located in the axil of a scale leaf, being typical therefore of axillary buds (McConnell and Barton, 1998).

\section{The hierarchy of buds in the cluster}

Buds were arranged in a spiral pattern along the stem axis of the cluster (first bud initial that developed adventitiously) with a single bud developing at each node at an approximate $90^{\circ}$ angle of phyllotaxy (Figs. 4B and 5). These individual buds developed sequentially from the proximal to distal end of the

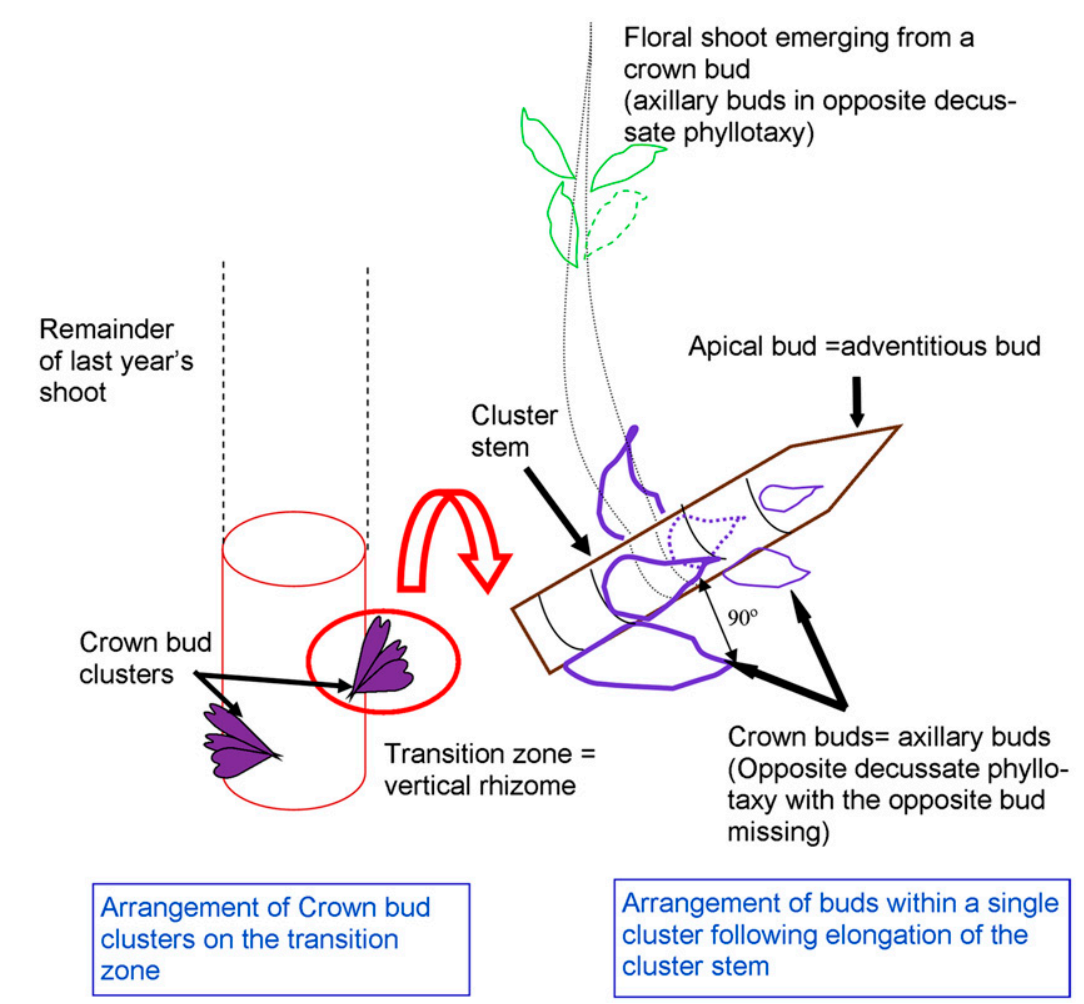

Fig. 5. Schematic diagram illustrating the arrangement of crown bud clusters on the transition zone, hierarchical arrangement of buds within the cluster, and origin of floral shoots of gentian. The diagram of the crown bud cluster represent an elongation of the compressed cluster stem similar to when treated with gibberellic acid $\left(\mathrm{GA}_{3}\right)$. Phyllotactic arrangement of crown buds (purple color) along the cluster stem differs that from the axillary buds (green color) of floral stems resulting from cluster following elongation of the cluster stem 
cluster stem (Figs. 4B and 5), resulting in the presence of buds of different sizes at any single point in time. This hierarchical arrangement within the cluster suggests the possibility for the existence of paradormancy from the apical bud and/or from other axillary buds within the cluster and therefore the potential variations in development of floral shoots in gentians.

Floral shoots of gentians present an opposite leaf arrangement at a node and an opposite decussate phyllotaxy (Bell and Bryan, 2008); hence, at each node, two axillary buds of a similar level of development were located (Samarakoon et al., 2013). In contrast, only one axillary bud at a node was stimulated to differentiate during the development of crown buds in a cluster (Fig. 5). Hence, gentian plants possess two different types of phyllotaxy, one within the bud cluster and the other on floral shoots (Fig. 5). Such variation in phyllotaxy was also noted in other plants (Bell and Bryan, 2008; Larson, 1975; Tomlinson and Murch, 2009), and, in some species, such differences denote a change from vegetative to reproductive phases (Poethig, 1990, 2003). In contrast to changes in phyllotaxis within the same shoot observed in these species, however, the phyllotactic arrangements within clusters and floral shoots appear to be predetermined in gentian. The reason for differences in phyllotaxis within the crown bud cluster and floral shoot will be of interest for further study. It would appear that gentians would be an interesting model plant for such studies.

\section{Conclusions}

As evident during the current study, development of a crown bud cluster was a multistep process, beginning with the development of the first bud initial within the bud cluster, which was adventitious (Fig. 5). Subsequent crown buds within the cluster developed as axillary buds from this first bud initial and were arranged spirally at $90^{\circ}$ with a single bud developing at each node on the cluster stem. Although under natural conditions, as a result of the compactness of the cluster stem, the hierarchical arrangement within the cluster was not visible, $\mathrm{GA}_{3}$ could be used to facilitate its elongation and, therefore, identification of their arrangement. Additionally, the methodologies used to distinguish the axillary buds from adventitious buds, i.e., location of their formation, presence of gaps in the vascular ring, vascular connections to the primary stem, and association with scale leaves, are concluded as useful strategies to address the origin of buds.

\section{Literature Cited}

Bell, A.D. and A. Bryan. 2008. Plant form: An illustrated guide to flowering plant morphology. Timber Press, London, UK.

Bowes, B.G. 1996. A colour atlas of plant structure. Manson Publ., London, UK.

Burrows, G. 2000. An anatomical study of epicormic bud strand structure in Eucalyptus cladocalyx (Myrtaceae). Austral. J. Bot. 48:233-245.

Burrows, G.E., S.K. Hornby, D.A. Waters, S.M. Bellairs, L.D. Prior, and D. Bowman. 2008. Leaf axil anatomy and bud reserves in 21 Myrtaceae species from northern Australia. Intl. J. Plant Sci. 169:1174-1186.

Chaffey, N., E. Cholewa, S. Regan, and B. Sundberg. 2002. Secondary xylem development in Arabidopsis: A model for wood formation. Physiol. Plant. 114:594-600.
Chiatante, D., G. Scippa, and A. Di Iorio. 2008. Anatomical investigations of resprouting in Cardopatum corymbosum L.(Asteraceae): A hemicryptophyta living on erosion-prone slopes in a Mediterranean climate. Plant Biosyst. 142:366-374.

Cutler, D.F., T. Botha, and D.W. Stevenson. 2008. Plant anatomy an applied approach. Blackwell, Malden, MA.

Del Tredici, P. 2001. Sprouting in temperate trees: A morphological and ecological review. Bot. Rev. 67:121-140.

Evert, R.F. 2006. Esau's plant anatomy. Meristems, cells, and tissues of the plant body: Their structure, function, and development. Wiley, Hoboken, NJ.

Gerrath, J.M., T.B. Guthrie, T.A. Zitnak, and U. Posluszny. 2008. Development of the axillary bud complex in Echinocystis lobata (Cucurbitaceae): Interpreting the cucurbitaceous tendril. Amer. J. Bot. 95:773-781.

Ho, T. and S. Liu. 2001. A worldwide monograph of Gentiana. Science Press, Beijing, China.

Kerstetter, R.A. and S. Hake. 1997. Shoot meristem formation in vegetative development. Plant Cell 9:1001-1010.

Larson, P.R. 1975. Development and organization of primary vascular system in Populus deltoides according to phyllotaxy. Amer. J. Bot. 62:1084-1099.

Mabberley, D.J. 2008. Mabberley's plant-book: A portable dictionary of plants, their classifications, and uses. Cambridge Univ. Press, Cambridge, UK.

McConnell, J.R. and M.K. Barton. 1998. Leaf polarity and meristem formation in Arabidopsis. Development 125:2935-2942.

Myers, G.A., C.A. Beasley, and L.A. Derscheid. 1964. Anatomical studies of Euphorbia esula L. Weeds 12:291-295.

Poethig, R.S. 1990. Phase change and the regulation of shoot morphogenesis in plants. Science 250:923-930.

Poethig, R.S. 2003. Phase change and the regulation of developmental timing in plants. Science 301:334-336.

Raju, M.V.S. 1975. Experimental studies on leafy spurge (Euphorbia esula L.). I. Ontogeny and distribution of buds and shoots on the hypocotyl. Bot. Gaz. 136:254-261.

Sachs, R. 1965. Stem elongation. Annu. Rev. Plant Physiol. 16:73-96.

Sachs, R.M., C.F. Bretz, and A. Lang. 1959. Shoot histogenesis: The early effects of gibberellin upon stem elongation in two rosette plants. Amer. J. Bot. 46:376-384.

Samarakoon, U.C., K.A. Funnell, D.J. Woolley, B.A. Ambrose, and E.R. Morgan. 2013. Anatomical investigations determining the origin of crown buds on the transition zone of gentians. N.Z. J. Bot. 51:264-274.

Samarakoon, U.C., K.A. Funnell, D.J. Woolley, G.K. Burge, and E.R. Morgan. 2010. Crown buds in gentians: Appearance, shoot emergence and development. Acta Hort. 937:483-490.

Samarakoon, U.C., K.A. Funnell, D.J. Woolley, and E.R. Morgan. 2012. Temperature impacts changes in crown buds and flowering of gentian 'Spotlight'. Sci. Hort. 143:49-55.

Saravitz, C.H., F.A. Blazich, and H.V. Amerson. 1993. Histology of in vitro adventitious bud development on cotyledons and hypocotyls of fraser fir. J. Amer. Soc. Hort. Sci. 118:163-167.

Tomlinson, P.B. and S.J. Murch. 2009. Wollemia nobilis (Araucariaceae): Branching, vasculature and histology in juvenile stages. Amer. J. Bot. 96:1787-1797.

Vesk, P.A. and M. Westoby. 2004. Funding the bud bank: A review of the costs of buds. Oikos 106:200-208.

Woo, S.M. and H.Y. Wetzstein. 2008. Morphological and histological evaluations of in vitro regeneration in Elliottia racemosa leaf explants induced on media with thidiazuron. J. Amer. Soc. Hort. Sci. 133:167-172. Yang, C., Z. Xu, J. Song, K. Conner, G. Vizcay Barrena, and Z.A. Wilson. 2007. Arabidopsis MYB26/MALE STERILE35 regulates secondary thickening in the endothecium and is essential for anther dehiscence. Plant Cell Online 19:534-538. 